Published in final edited form as:

Sleep Med Clin. 2009 September ; 4(3): 393-406. doi:10.1016/j.jsmc.2009.04.007.

\title{
PEDIATRIC POLYSOMNOGRAPHY
}

Suzanne E. Beck, M.D. and Carole L. Marcus, M.B.B.Ch.

Sleep Center, The Children's Hospital of Philadelphia, University of Pennsylvania School of Medicine, Philadelphia, Pennsylvania

\section{Keywords}

obstructive sleep apnea; scoring; child; sleep-disordered breathing

\section{INDICATIONS FOR PEDIATRIC POLYSOMNOGRAPHY}

\section{Obstructive Sleep Apnea Syndrome (OSAS)}

OSAS is the most common indication for polysomnography. OSAS is common in the pediatric age group, occurring in approximately $2 \%$ of young children (1). The American Academy of Pediatrics recommends that all children be screened by history for snoring (2), recognizing that OSAS is common and is frequently under-diagnosed. Whether or not primary snoring per se results in morbidity is controversial, and is beyond the scope of this chapter. However, it has been well established that clinical history alone can not distinguish primary snoring from OSAS in children (2;3). Thus, both the American Thoracic Society (4) and the American Academy of Pediatrics (2) recommend polysomnography as the diagnostic test of choice for children with suspected OSAS.

In most cases of pediatric OSAS, children present with signs or symptoms of obstructive breathing patterns during sleep, including snoring, labored breathing, witnessed apnea, gasping, mouth-breathing, or sleeping in unusual positions (such as with the neck hyperextended). Failure to thrive or signs of right sided heart failure may be present in severe cases. Associated daytime symptoms can be difficult to elicit. Unlike adults in whom excessive daytime sleepiness is often the presenting complaint, younger children tend to manifest daytime sleepiness as hyperactivity or inability to concentrate, leading to poor school performance or behavioral issues. Most children with obstructive sleep apnea have a normal physical exam. However, physical findings of retrognathia, oropharyngeal crowding, high arched palate, adenotonsillar hypertrophy, mouth breathing or stertor at rest suggest the need for further evaluation for OSAS. Prematurity, hypotonia (e.g., children with cerebral palsy or muscular dystrophy, Down syndrome) or craniofacial anomalies are risk factors for OSAS. We believe that polysomnography is indicated in any child who snores and has labored breathing during sleep, and who has any predisposing physical exam findings or daytime symptoms. Polysomnography is the gold standard for the diagnosis of OSAS. Other diagnostic studies such as nocturnal oximetry (5), videotaping (6) and nap studies (7) may be helpful if positive,

Address for Correspondence: Carole L. Marcus, M.B.B.Ch., The Children's Hospital of Philadelphia, Pulmonary Division, 5th floor Wood, 34th \& Civic Center Blvd, Philadelphia, PA 19104, Phone: 267-426-5842, Fax: 215-590-3500, E-mail: marcus@email.chop.edu. Coauthor address: Suzanne E. Beck, M.D., The Children's Hospital of Philadelphia, Pulmonary Division, 5th floor Wood, 34th \& Civic Center Blvd, Philadelphia, PA 19104, Phone: 267-426-5842, Fax: 215 - 590-3500,E-mail: becksu@email.chop.edu

Publisher's Disclaimer: This is a PDF file of an unedited manuscript that has been accepted for publication. As a service to our customers we are providing this early version of the manuscript. The manuscript will undergo copyediting, typesetting, and review of the resulting proof before it is published in its final citable form. Please note that during the production process errors may be discovered which could affect the content, and all legal disclaimers that apply to the journal pertain. 
but underestimate the presence of OSAS (2;3), in part because they may not capture REM sleep, during which the majority of obstructive events occur (8) (Figure 1). Finally, direct observation of a sleeping child who is obstructing may be diagnostic of OSAS, but does not quantitate the severity of OSAS and thus cannot predict perioperative risk or the likelihood of persistent abnormalities post-operatively.

\section{Central Apnea, Periodic Breathing and Central Hypoventilation Syndromes}

Pediatric polysomnography is indicated to evaluate infants and children with suspected pathologic central apnea, periodic breathing or central hypoventilation. These children may present with cyanosis, observed apnea during sleep, daytime symptoms, apparent lifethreatening events, post-anesthetic respiratory depression or cor pulmonale. It is crucial to monitor end-tidal $\mathrm{PCO}_{2}$ levels to evaluate for hypoventilation, which if not detected and treated promptly may lead to poor developmental outcomes.

\section{Neuromuscular Disorders}

Polysomnography is useful to evaluate underlying cardiorespiratory function in children with neuromuscular disorders. The timing of the study in the patient's clinical course is variable and is determined by their physician's interpretation of signs and symptoms (9). In addition to evaluation of complaints of difficulty breathing during sleep, a polysomnogram is indicated to detect sleep disordered breathing if there has been a change in growth velocity, developmental progress, daytime symptoms (e.g., sleepiness, headache), pulmonary function (10), development of daytime hypercapnia (11), polycythemia or heart failure. Children with respiratory muscle weakness may not show signs of labored breathing during sleep and may not manifest airway obstruction by snoring. $\mathrm{CO}_{2}$ monitoring is crucial during polysomnography in these patients to evaluate for sleep hypoventilation.

\section{Chronic Lung Disease}

Polysomnography can be used to evaluate for nocturnal hypoventilation and hypoxemia in infants and children with chronic lung disease, as well as to titrate supplemental oxygen. Children with chronic lung disease may have normal arterial oxygen saturation values during wakefulness, but desaturate during sleep (12). In infants with bronchopulmonary dysplasia, maintaining arterial oxygen saturation levels $\geq 93 \%$ during sleep results in improved growth (13). Unattended overnight pulse oximetry monitoring can be used to assess oxygenation, but may be limited by motion artifact, and oxygen cannot be titrated during these studies; however, home oximetry studies have been proven to underestimate the degree of desaturation (14).

\section{Continuous Positive Airway Pressure (CPAP) Ventilator Titration Studies}

Pediatric polysomnography is used to titrate CPAP and bilevel pressures, as well as home ventilators, in children. One of the main differences in pediatric CPAP titration studies compared to adults is that split night studies (diagnostic studies converted to titrations after demonstration of clinically significant OSAS) are not commonly performed, for several reasons. Often, the children referred to the sleep lab have complex medical issues, and the decision to initiate PAP is multifaceted and is best done in an office setting. In addition, since adenotonsillectomy is the first line of treatment for childhood OSAS, CPAP is often not necessary. Most importantly, placing CPAP on a child for the first time in the middle of the night can be frightening and disturbing for the child. This can result in behavioral issues which will unfavorably influence future CPAP adherence. A behavioral program with desensitization is preferable. For ventilator titration studies, the presence of a respiratory therapist during the study is advisable. 


\section{Tracheostomy Decannulation}

Polysomnography is a useful tool to assess functional airway obstruction in children who is thought to be ready for tracheostomy decannulation. In pediatrics, tracheostomies are often placed temporarily, e.g., in a neonate requiring prolonged ventilatory support, or while awaiting adequate airway growth for an infant to tolerate airway reconstruction. Children may breathe adequately when the tracheostomy tube is capped during wakefulness, but develop upper airway obstruction due to hypotonia during sleep (15). During these polysomnograms, the patient is monitored initially with the tracheostomy uncapped. The tracheostomy tube is then capped and airflow and end-tidal PCO2 are monitored via the nose and mouth. It is necessary that oxygen, if required for chronic lung disease, be weaned to low flow so that it can be delivered through a nasal cannula. During the study, careful attention is paid to work of breathing and the presence of obstructive apneas or hypopneas. The lab staff must be trained in tracheostomy care, and should uncap the tracheostomy tube immediately if adverse events are noted. If there is concern that the child may not tolerate the procedure, the study can be done as a bedside study in the intensive care unit. Tracheostomy tube capping studies should only be done in patients who have tolerated capping of the tracheostomy during wakefulness. Ideally, the tracheostomy tube should be downsized prior to the study.

\section{Parasomnias}

A common complaint evaluated in a pediatric sleep center is frequent night awakenings. In most cases, polysomnography is not indicated to evaluate this complaint. Rather, a good history will help determine if these night awakenings are due to sleep terrors or confusional arousals versus behavioral insomnia of childhood or some other cause. However, there are uncommon cases where polysomnography is useful in determining whether there is a pathologic cause precipitating the night waking, such as gastroesophageal reflux or OSAS. In some unusual cases, polysomnography can be helpful in differentiating parasomnias from seizures, hysterical conversion reactions or malingering (e.g., for school avoidance). In these cases, videotaping and good documentation by the sleep technologist are essential. Examining the EEG for epileptiform activity during unusual movements during sleep is useful in differentiating true seizure activity from other motor activity during sleep.

\section{Restless Legs Syndrome And Periodic Limb Movement Disorder (PLMD)}

It is our practice to place limb leads on every infant and child having a polysomnogram. Polysomnography is useful to evaluate for PLMD in young children with symptoms suggestive of restless legs syndrome in whom a definitive history can be hard to elicit; however it is not indicated in straightforward cases.

\section{Excessive Daytime Sleepiness}

In most cases of excessive daytime sleepiness, history, sleep diaries or actigraphy reveal the cause (such as insufficient sleep or poor sleep hygiene) and polysomnography is unnecessary. However, polysomnography is indicated in the evaluation of excessive daytime sleepiness if the history elicits suspicion of a pathologic cause such as OSAS, narcolepsy, PLMD or nocturnal seizures. If narcolepsy is suspected, a multiple sleep latency test (MSLT) is indicated. Normal, school-aged children are physiologically unlikely to fall asleep during the day, and thus age-appropriate normative data must be used to interpret the MSLT. The tendency to fall asleep during the day increases with increasing pubertal Tanner stage (16). Some investigators have recommended using MSLTs with naps longer than 20 minutes when young children are studied for research purposes. However, the clinical utility of this longer MSLT protocol for the diagnosis of narcolepsy in children is unknown. Infants usually enter sleep via REM, but in older children, REM-onset naps are suggestive of narcolepsy. In children younger than 5 
years of age, in whom napping is commonplace, MSLTs are hard to perform and normative data are unavailable.

\section{Ambulatory And Unattended Polysomnography}

There are no randomized, controlled trials and limited information on pediatric unattended home polysomnography. Jacob et al used a specialized, non-commercial polysomnography system in a carefully selected population in the home, and compared this to in-laboratory recordings. They reported adequate data, with a close correlation between home and laboratory values (17). In contrast, Poels et al studied children aged 2-7 years of age, using a commercial system, and found that only $29 \%$ of recordings were successful (18). Goodwin et al reported the feasibility of performing home unattended studies in selected patients as part of a research protocol which involved sending a team to the home to hook up the patient; the initial failure rate was $9 \%$ (19). Clearly, further studies are needed.

\section{CREATING A CHILD-FRIENDLY LABORATORY (Figure 2)}

Polysomnography can be challenging in pediatrics because children have a limited ability to cooperate with the setup, and may have trouble sleeping in a strange environment. There are many things a sleep laboratory can do to ease the burden on the child, the family and the technologists, and to improve the diagnostic quality of the polysomnogram.

Our approach is to have a mindset of family-centered care, with the parent remaining with the child at all times and the least amount of trauma created for the child. The goal of the lab should be to put the needs of the child first and the needs of the lab and technicians second. The environment in the waiting room and in the "bedroom" should be child-friendly. In a combined adult-pediatric lab, consider a separate waiting area for children, as they may be intimidated by seeing older or ill-appearing adults just before bedtime. A parent should stay with the child, and there should be comfortable accommodations for the parent including a bed in the same room, and shower facilities. The patient bed should be age- and developmentally appropriate (e.g., a crib for infants and toddlers, and side rails for the young or for children with special needs). The type of bed required should be known ahead of time so that the room is ready when the patient arrives.

Psychological preparation should be offered to the child and parent prior to the sleep study. This often starts with the clinician who orders the study explaining the procedure and reason for the study in detail. The preparation is reinforced during the scheduling process, where parents are reminded of the procedure and allowed to ask questions. A visit to the sleep lab for a tour prior to the sleep study can be very helpful in easing anxiety associated with the study.

Staffing and lab hours might need to be extended for pediatric polysomnograms as children go to bed earlier than adults and need more sleep (e.g., an eight year old typically needs 10 hours for sleep a night). Ideally, there should be a 1:1 technologist:patient ratio during the patient hookup. Some laboratories have used swing shifts during the evening in order to accomplish this. The child should be allowed to sit on the parent's lap and should not be forced to lie down for the hookup. The technician should partner with the parent and the child during the setup and engage the child as much as possible, assigning roles, giving choices, and encouraging age and developmentally appropriate coping strategies. Each step of the hookup should be explained in a child-friendly manner. Lots of praise and smiles should be given out. A few laboratories have child life specialists present during the hookup. The lab should be equipped with a "distraction box" full of toys such as soap bubble kits, stickers and books to be used during the hook up (20). Although watching television and other electronic screens before bedtime is not good sleep hygiene, making an exception (carefully explained to the parents as such) for polysomnography and having the child watch a video or play video games during 
hookup can be a powerful distraction. Instead of the hookup proceeding from head to toe, the technician should place the least invasive sensors on first (e.g., leg leads) and save the more noxious ones (EEG, nasal cannula) for later. If necessary, the nasal cannula can be placed after the child falls asleep.

During the night, the technologist:patient ratio should be 1:1 or 1:2, depending on the type of study being performed. Children should be allowed to sleep in their usual position.

The reader is encouraged to read reference (20) for a detailed description of making polysomnography more child friendly.

\section{PEDIATRIC POLYSOMNOGRAPHIC TECHNIQUES}

The new American Academy of Sleep Medicine (AASM) scoring manual (21) is the first to clearly delineate pediatric scoring criteria, and the AASM mandates the use of this manual in all accredited sleep labs.

The physiologic parameters typically measured during pediatric polysomnography are similar to those measured during polysomnography in adults, with a few exceptions. Recommended sampling rates and filter settings for each channel can be found in the AASM manual (21). The characteristic montage includes:

- Electroencephalogram (EEG): The AASM recommends F4-M1, C4-M1 and O2-M1; contralateral leads are typically applied as well (F3-M2, C3-M2 and O1-M2).

- Electromyogram (EMG): Submental and bilateral tibial

- Electrooculogram (right and left)

- $\quad$ ECG

- Nasal pressure

- Oronasal airflow (thermistry)

- End-tidal $\mathrm{PCO}_{2}$

- Arterial oxygen saturation $\left(\mathrm{SpO}_{2}\right)$ with pulse waveform

- Chest and abdominal wall motion

- Body position monitor

- Snoring microphone (optional)

- Video

\section{EEG Monitoring}

Children have high amplitude brain waves. Thus, EEG recordings may need a sensitivity of $10-15 \mu \mathrm{V} / \mathrm{mm}$, as compared to $5 \mu \mathrm{V} / \mathrm{mm}$ in adults. As infants and young children have smaller heads than adults, chin EMG electrodes may need to be placed $1 \mathrm{~cm}$ apart rather than $2 \mathrm{~cm}$ apart, and electrooculographic leads may need to be placed $0.5 \mathrm{~cm}$ from the outer canthi. Because children frequently displace leads during the night, applying redundant leads (such as the contralateral EEG leads, or several monitors of airflow) can obviate the need to awaken the child during the night to reattach leads. Extended EEG montages are used if nocturnal seizures are suspected. However, this procedure extends the setup time. Furthermore, the more leads attached, the more difficulty a child may have falling asleep. 


\section{Airflow Monitoring}

The use of multiple measures of airflow is highly recommended, as signals are often lost due to moisture in the sensors, secretions, displacement of the sensor by the child or sucking artifact. In particular, it is crucial to include a sensor for oral breathing, as many children with OSAS have an enlarged adenoid and therefore breathe through their mouth. All of the sensors used have both advantages and disadvantages (Table 1). In our laboratory, we simultaneously measure oronasal thermistry (primarily to detect mouth-breathing), nasal pressure (primarily as a semi-quantitative assessment of airflow), end-tidal $\mathrm{PCO}_{2}$ (primarily as a measure of hypercapnia) and respiratory inductance plethysmography (primarily to assess respiratory effort). We measure nasal pressure and end-tidal $\mathrm{PCO}_{2}$ using a single nasal cannula with a distal $\mathrm{Y}$-connection to a pressure manometer and a capnometer, and combine this with a very thin, flat thermistor. This system is tolerated by even very young children. For CPAP studies, we use the pneumotachometer within the CPAP circuit as the primary sensor of airflow.

\section{Oximetry}

Oximeter signal averaging time should be no more than 3 seconds (21). Children tend to move frequently during sleep, so the monitoring of the pulse waveform in addition to the saturation value is helpful in distinguishing motion artifact from true desaturation. Most pulse oximeters provide an output for the plethysmographic pulse waveform. This output can also be used for more sophisticated analyses, such as the measurement of pulse transit time (22). Oximeters with artifact-reduction algorithms can be very useful (23).

\section{Capnometry}

Most adult sleep laboratories do not measure carbon dioxide $\left(\mathrm{CO}_{2}\right)$. However, $\mathrm{CO}_{2}$ measurements are usually obtained in pediatric studies, and can be extremely useful in identifying obstructive hypoventilation (see Scoring section, below). In addition, the measurement of $\mathrm{CO}_{2}$ is useful in children with chronic lung disease or those receiving ventilatory support. It is especially important to measure $\mathrm{CO}_{2}$ when supplemental oxygen is initiated in the sleep lab, as some patients may be dependent on their hypoxic drive to breathe. Adding oxygen without monitoring $\mathrm{CO}_{2}$ may lead to worsening hypoventilation, and clinical deterioration of the patient (24).

Measurements of $\mathrm{CO}_{2}$ have been used in two contexts during polysomnography: as an indicator of airflow obstruction, and for quantitative measurement of hypoventilation. As a measure of airflow, end-tidal $\mathrm{CO}_{2}$ is often oversensitive, and is therefore not recommended other than as an adjunct signal. Thus, in pediatric laboratories, end-tidal $\mathrm{PCO}_{2}$ is usually measured as an indicator of hypoventilation rather than obstruction. End-tidal $\mathrm{PCO}_{2}$ can be measured directly from a tracheostomy or endotracheal tube, or as a side-stream measure from a nasal cannula. It is imperative that a good signal, consisting of a plateau during exhalation be obtained (Figure 3 ). If not, the measure can severely underestimate the actual $\mathrm{PCO}_{2}$. Furthermore, software should be used that provides the peak $\mathrm{PCO}_{2}$ rather than random time points during a breath. To maintain a good signal, the technologist needs to be vigilant about clearing secretions and humidity from the line. In children who mouth-breathe, satisfactory signals can sometimes be obtained by placing the cannula over the mouth. It is common to see a single breath with an elevated end-tidal $\mathrm{PCO}_{2}$ value, especially after sighs or body movements, when previously atelectatic alveoli re-expand. Therefore, the percentage of total sleep time with hypercapnia is more important than the peak end-tidal $\mathrm{PCO}_{2}$ value for the night. End-tidal $\mathrm{PCO}_{2}$ values may be inaccurate in patients with obstructive lung disease with long time constants, such as patients with advanced cystic fibrosis.

An alternative measurement option for evaluating hypoventilation is transcutaneous $\mathrm{PCO}_{2}$. The transcutaneous electrode warms the skin, thereby arteriolizing the capillary blood flow. 
The sensor must be moved during the night to prevent skin burns. In contrast to end-tidal measurements, transcutaneous measurements can be slow-reacting, and therefore provide a trend rather than a breath-by-breath measurement. However, transcutaneous measurements may be preferable to end-tidal measurements in children with advanced obstructive lung disease, infants with rapid respiratory rates, children who breathe through their mouth and children receiving CPAP, in whom the CPAP airflow may interfere with end-tidal measurements.

Many children, particularly those less than three years of age, have a pattern of persistent, partial upper airway obstruction associated with hypercapnia and/or hypoxemia, rather than cyclic discrete obstructive apneas. This has been termed "obstructive hypoventilation." (4) Most studies comparing end-tidal and transcutaneous $\mathrm{PCO}_{2}$ to arterial samples have been performed in the intensive care unit or during anesthesia, rather than in sleep laboratories. In general, these studies show a good correlation between the transcutaneous/end-tidal and arterial values, with a small bias evident in subjects without lung disease. In general, end-tidal values tended to underestimate arterial $\mathrm{CO}_{2}$, with the largest discrepancies occurring in hypercapnic subjects or in subjects with respiratory disease. Transcutaneous values tended to have a smaller bias compared to arterial values than the end-tidal $\mathrm{PCO}_{2}$ measurements, but tended to overestimate the $\mathrm{PCO}_{2}$. Please see reference (25) for details.

\section{Respiratory Effort}

Chest and abdominal wall motion can be measured in a number of ways. Respiratory inductance plethysmography is the preferred method, and is typically used in the uncalibrated mode in children, as calibration procedures would need to be repeated after body movements. Other sensors that have been used include piezo-electric belts, which are provided with many commercial polysomnography systems, intercostal EMG, and esophageal pressure monitoring. In one non-randomized study of normal children, paradoxical breathing was seen much more commonly with piezo-electric belts than with respiratory inductance plethysmography (26). Esophageal pressure monitoring is rarely used as it is invasive, and the nasal pressure flow signal is often used as a surrogate when the upper airway resistance syndrome is suspected.

\section{Body Position}

Body position is frequently measured during polysomnography, although the measurement of body position is less important in young children than in adults, as OSAS is less positional $(27 ; 28)$.

\section{Esophageal pH}

Esophageal $\mathrm{pH}$ is occasionally measured to determine whether gastroesophageal reflux is contributing to night wakings, apnea or desaturation. $\mathrm{pH}$ probe insertion is more invasive than the rest of the leads on a polysomnogram and takes specialized skill; placement must be confirmed by radiograph. The percentage of total sleep time with $\mathrm{pH}<4$, and the number and length of $\mathrm{pH}$ drops $<4$ can be quantified, and reviewed for an association with respiratory disturbances.

\section{Videotaping}

Videotaping can be extremely helpful in the assessment of parasomnias, seizures and unusual respiratory events. In rare cases, such as a very autistic child who refuses many of the monitoring leads, videotaping can be a valuable diagnostic tool. It may also be useful at times by revealing unusual parental interactions. In the authors' experience, videotapes and technologist's observations have revealed cases where a lead radiology vest was used by parents to restrain a neurologically-impaired child's nocturnal movements; a cardboard box 
over the child's head was substituted for an oxygen hood; a teenager complaining of daytime fatigue wrapped her entire face and body in a sheet cocoon, resulting in increased inspired and end-tidal $\mathrm{PCO}_{2}$ levels; and an infant admitted with cyanotic spells had a bible placed over his face during sleep (Figure 4).

\section{PEDIATRIC POLYSOMNOGRAPHY SCORING}

Pediatric scoring rules are detailed in the AASM manual (21). This chapter will highlight the differences between adult and pediatric scoring rules.

\section{Sleep Architecture}

The EEG changes considerably with age. The new AASM rules, with a few minor modifications, are applicable to pediatric patients older than 2 months post-term. In infants younger than 2 months of age, Anders criteria, which rely heavily on behavioral observations in addition to EEG, should be used (29). Sleep spindles, K complexes and slow wave activity are typically first noted at 2-3 months, 4-6 months and 4-5 months post-term, respectively, and thereafter become more prominent. If these distinguishing EEG characteristics cannot be discerned after 2 months of age, sleep should be scored as stage N (nonREM) and R (REM). By 6 months of age, most infant studies can be scored using the adult nonREM stages (i.e., stages N1, N2 and N3). However, the EEG continues to show differences from the adult EEG, with a higher amplitude, and a slower dominant posterior rhythm than the alpha rhythm seen in adults. For further details, please see reference (30).

It should be recognized that the amount of REM and slow wave sleep changes dramatically during infancy, childhood and adolescence. In infants, it is normal to enter sleep via REM. The amount of REM sleep as a percentage of total sleep time decreases during infancy and childhood. The amount of slow wave sleep also decreases during childhood, particularly during adolescence.

\section{Arousals}

Arousal scoring rules are the same for children as for adults. Children have a higher arousal threshold than adults, so it is common for them to have obstructive events that are not associated with EEG arousals (31).

\section{Respiratory}

Respiratory scoring in children is quite different from that in adults. Pediatric scoring must be used for children $\leq 12$ years of age. As there is a paucity of data for adolescents, the use of pediatric scoring criteria for teenagers between 13-17 years of age is optional. However, small studies that incorporated adolescents indicate that their breathing patterns during sleep are similar to that of younger children, and hence, the use of pediatric scoring criteria would be appropriate (32-35). Adult criteria are used for patients $\geq 18$ years of age.

In adults, apneas and hypopneas are only scored if they are $\geq 10$ seconds duration. Children have a faster respiratory rate than adults, and a lower functional residual capacity. They are therefore more likely to desaturate and suffer physiologic consequences from brief apneas. Because of this, obstructive apneas and hypopneas are scored if they are at least 2 breaths duration, even if they are $<10$ seconds duration (21) (Figure 5). Hypopneas are defined as a $50 \%$ reduction in airflow associated with either arousal or $\geq 3 \%$ desaturation (21). In contrast to adults, the AASM does not recommend any alternative Medicare scoring rules for hypopneas. Obstructive events in children occur primarily during REM sleep (8). Thus, if sufficient REM sleep is not obtained during a polysomnogram, the degree of OSAS is likely to be underestimated. 
Some children, especially very young children, have a pattern of persistent partial upper airway obstruction associated with hypercapnia and desaturation, rather than discrete obstructive apneas or hypopneas. This pattern has been termed "obstructive hypoventilation" (4) (Figure 6). Obstructive hypoventilation differs from hypopneas in that a reduction in airflow may not be detected using usual airflow sensors, and events may be very long (many minutes). It can be differentiated from hypoventilation secondary to central nervous system abnormalities or pulmonary disease by the presence of snoring and paradoxical respiratory efforts. In addition, although hypoventilation from any cause is usually worse during sleep than wakefulness, in patients with obstructive hypoventilation the discrepancy between sleep and wakefulness is very large.

Respiratory effort related arousals (RERA) are not scored in all laboratories. Scoring details can be found in the AASM manual (21). The prevalence of the upper airway resistance syndrome during childhood is not known, but many practitioners believe that it is rare, and that these children tend to exhibit mild forms of classic sleep-disordered breathing that can be detected using conventional polysomnographic acquisition and scoring techniques, including the monitoring of nasal pressure and end-tidal $\mathrm{PCO}_{2}$.

Central apneas are common during sleep in children. Children have an active Hering-Breuer reflex (compensatory central respiratory pauses following the stimulation of pulmonary stretch receptors), and frequently have central apneas following sighs and movements, as well as during REM sleep. Central apneas or periodic breathing at sleep-onset is relatively uncommon. Because long central apneas are frequently seen in normal children, central apneas are only scored if they are $\geq 20$ seconds duration, or shorter, but associated with either arousal or $\geq 3 \%$ desaturation (21).

Periodic breathing occurs relatively frequently in premature infants or children at high altitude, and is occasionally seen in older children with central nervous system abnormalities, or as a brief normal phenomenon at sleep onset. Periodic breathing is defined as $>3$ episodes of central apnea lasting $>3$ seconds each, and separated by $\leq 20$ seconds of normal breathing (21). It is different from Cheyne-Stokes breathing in that it typically lacks a waxing and waning pattern (Figure 7).

Central and obstructive apneas have very different pathophysiologic mechanisms and treatments. Hence, the obstructive and central event indices should be presented separately, rather than being combined as a respiratory disturbance index. Mixed apneas and hypopneas are included in the obstructive index.

\section{REPRODUCIBILITY OF PEDIATRIC POLYSOMNOGRAPHIC RESULTS}

Several studies have examined polysomnographic reproducibility. Infants do not display a first night effect (36). When studied on 2 consecutive nights, older children have an increased sleep latency and decreased sleep efficiency on the first night, and may also show changes in REM sleep, consistent with a first night effect $(37 ; 38)$. However, differences in respiratory parameters from one night to another are minimal, and not clinically significant $(37 ; 38)$. When polysomnography was repeated over several weeks, or even after a year in children with primary snoring, some very minor changes were noted in the apnea hypopnea index, but not enough to be clinically important $(39 ; 40)$. Therefore, one night of polysomnography is adequate for clinical purposes, although several nights of recording may be needed in order to evaluate sleep architecture for research purposes. 


\section{CLINICAL IMPLICATIONS OF PEDIATRIC POLYSOMNOGRAPHIC SCORING}

Tables 2 and 3 show suggested normative data for the different polysomnographic variables. It should be emphasized that these are statistical norms rather than clinical criteria upon which to base treatment decisions. There are very few studies assessing the polysomnographic predictors of morbidity in children, and these outcome studies need to be performed before clear clinical recommendations can be made. That being said, children do tend to have clinical complications of OSAS with a much lower apnea hypopnea index (AHI) than adults, and many centers will treat children with an AHI in the $2-5 / \mathrm{hr}$ range. An AHI of 10/hr, which is considered mild in adults, is generally considered to be moderately severe in children (39). An NIH-funded, multicenter randomized trial (the Childhood Adenotonsillectomy [CHAT] study) is currently underway to evaluate neurocognitive morbidity associated with mild to moderate OSAS in children, and whether surgical intervention influences neurocognitive outcomes. Thus, more information should become available over the next few years.

\section{Summary}

Pediatric polysomnography is the diagnostic study of choice to evaluate for obstructive sleep apnea in children, and to evaluate cardiorespiratory function in infants and children with chronic lung disease or neuromuscular disease when indicated. It is helpful to investigate atypical cases of parasomnias. It is important to understand that children are not just small adults when being studied in a sleep lab; they require a child friendly atmosphere and approach, need smaller and specialized equipment, and due to developmental and physiological differences from adults, have age-adjusted rules for the scoring and interpretation of polysomnograms.

\section{Acknowledgments}

The authors would like to thank the patients and families in our Sleep Center who have given us the experience to become proficient in pediatric sleep medicine, the technicians in the sleep laboratory who make hooking a child up for a sleep study look fun and easy, and especially to Joe Traylor, RPSGT, for his expertise in preparing the figures for this paper.

This research was supported by the National Institutes of Health R01 HL58585

\section{References}

1. Redline S, Tishler PV, Schluchter M, Aylor J, Clark K, Graham G. Risk factors for sleep-disordered breathing in children. Associations with obesity, race, and respiratory problems. Am J Respir Crit Care Med 1999;159:1527-1532. [PubMed: 10228121]

2. American Academy of Pediatrics. Clinical practice guideline: diagnosis and management of childhood obstructive sleep apnea syndrome. Pediatrics 2002;109(4):704-712. [PubMed: 11927718]

3. Schechter MS. Technical report: diagnosis and management of childhood obstructive sleep apnea syndrome. Pediatrics 2002;109(4):E69. [PubMed: 11927742]

4. American Thoracic Society. Standards and indications for cardiopulmonary sleep studies in children. Am J Respir Crit Care Med 1996;153:866-878. [PubMed: 8564147]

5. Brouillette RT, Morielli A, Leimanis A, Waters KA, Luciano R, Ducharme FM. Nocturnal pulse oximetry as an abbreviated testing modality for pediatric obstructive sleep apnea. Pediatrics 2000;105 (2):405-412. [PubMed: 10654964]

6. Sivan Y, Kornecki A, Schonfeld T. Screening obstructive sleep apnoea syndrome by home videotape recording in children. Eur Respir J 1996;9(10):2127-2131. [PubMed: 8902478]

7. Marcus CL, Keens TG, Ward SL. Comparison of nap and overnight polysomnography in children. Pediatr Pulmonol 1992;13(1):16-21. [PubMed: 1589307]

8. Goh DYT, Galster P, Marcus CL. Sleep architecture and respiratory disturbances in children with obstructive sleep apnea. Am J Respir Crit Care Med 2000;162:682-686. [PubMed: 10934106] 
9. Finder JD, Birnkrant D, Carl J, Farber HJ, Gozal D, Iannaccone ST, et al. Respiratory care of the patient with Duchenne muscular dystrophy: ATS consensus statement. Am J Respir Crit Care Med 2004;170 (4):456-465. [PubMed: 15302625]

10. Toussaint M, Steens M, Soudon P. Lung function accurately predicts hypercapnia in patients with Duchenne muscular dystrophy. Chest 2007;131(2):368-375. [PubMed: 17296635]

11. Hukins CA, Hillman DR. Daytime predictors of sleep hypoventilation in Duchenne muscular dystrophy. Am J Respir Crit Care Med 2000;161(1):166-170. [PubMed: 10619815]

12. Moyer-Mileur LJ, Nielson DW, Pfeffer KD, Witte MK, Chapman DL. Eliminating sleep-associated hypxemia improves growth in infants with bronchopulmonary dysplasia. Pediatrics 1996;98:779783. [PubMed: 8885961]

13. Groothuis JR, Rosenberg AA. Home oxygen promotes weight gain in infants with bronchopulmonary dysplasia. Am J Dis Child 1987;141(9):992-995. [PubMed: 3618573]

14. Wiltshire N, Kendrick AH, Catterall JR. Home oximetry studies for diagnosis of sleep apnea/ hypopnea syndrome: limitation of memory storage capabilities. Chest 2001;120(2):384-389. [PubMed: 11502633]

15. Tunkel DE, McColley SA, Baroody FM, Marcus CL, Carroll JL, Loughlin GM. Polysomnography in the evaluation of readiness for decannulation in children. Arch Otolaryngol Head Neck Surg 1996;122(7):721-724. [PubMed: 8663942]

16. Carskadon MA, Harvey K, Duke P, Anders TF, Litt IF, Dement WC. Pubertal changes in daytime sleepiness. Sleep 1980;2(4):453-460. [PubMed: 7403744]

17. Jacob SV, Morielli A, Mograss MA, Ducharme FM, Schloss MD, Brouillette RT. Home testing for pediatric obstructive sleep apnea syndrome secondary to adenotonsillar hypertrophy. Pediatr Pulmonol 1995;20(4):241-252. [PubMed: 8606854]

18. Poels PJ, Schilder AG, van den BS, Hoes AW, Joosten KF. Evaluation of a new device for home cardiorespiratory recording in children. Arch Otolaryngol Head Neck Surg 2003;129(12):12811284. [PubMed: 14676152]

19. Goodwin JL, Enright PL, Kaemingk KL, Rosen GM, Morgan WJ, Fregosi RF, et al. Feasibility of using unattended polysomnography in children for research--report of the Tucson Children's Assessment of Sleep Apnea study (TuCASA). Sleep 2001;24(8):937-944. [PubMed: 11766164]

20. Zaremba EK, Barkey ME, Mesa C, Sanniti K, Rosen CL. Making polysomnography more "child friendly:” a family-centered care approach. J Clin Sleep Med 2005;1(2):189-198. [PubMed: 17561635]

21. Iber, C., editor. The AASM Manual for the Scoring of Sleep and Associated Events: Rules, Terminology and Technical Specification. American Academy of Sleep Medicine; 2007. Ref Type: Serial (Book, Monograph)

22. Katz ES, Lutz J, Black C, Marcus CL. Pulse transit time as a measure of arousal and respiratory effort in children with sleep-disordered breathing. Pediatr Res 2003;53(4):580-588. [PubMed: 12612196]

23. Brouillette RT, Lavergne J, Leimanis A, Nixon GM, Ladan S, McGregor CD. Differences in pulse oximetry technology can affect detection of sleep-disorderd breathing in children. Anesth Analg 2002;94(1 Suppl):S47-S53. [PubMed: 11900039]

24. Marcus CL, Carroll JL, Bamford O, Pyzik P, Loughlin GM. Supplemental oxygen during sleep in children with sleep- disordered breathing. Am J Respir Crit Care Med 1995;152(4 Pt 1):1297-1301. [PubMed: 7551385]

25. Redline S, Budhiraja R, Kapur V, Marcus CL, Mateika JH, Mehra R, et al. The scoring of respiratory events in sleep: reliability and validity. J Clin Sleep Med 2007;3(2):169-200. [PubMed: 17557426]

26. Traeger N, Schultz B, Pollock AN, Mason T, Marcus CL, Arens R. Polysomnographic values in children 2-9 years old: additional data and review of the literature. Pediatr Pulmonol 2005;40(1):2230. [PubMed: 15858805]

27. Fernandes do Prado LB, Li X, Thompson R, Marcus CL. Body position and obstructive sleep apnea in children. Sleep 2002;25(1):66-71. [PubMed: 11833863]

28. Dayyat E, Maarafeya MM, Capdevila OS, Kheirandish-Gozal L, Montgomery-Downs HE, Gozal D. Nocturnal body position in sleeping children with and without obstructive sleep apnea. Pediatr Pulmonol 2007;42(4):374-379. [PubMed: 17352403] 
29. Anders, T.; Emde, R.; Parmelee, A., editors. A manual of standardized terminology, techniques and criteria for scoring of states of sleep and wakefulness in newborn infants. UCLA Brain Information Service, NINDS Neurological Information Network; 1971. Ref Type: Serial (Book, Monograph)

30. Grigg-Damberger M, Gozal D, Marcus CL, Quan SF, Rosen CL, Chervin RD, et al. The visual scoring of sleep and arousal in infants and children. Journal of Clinical Sleep Medicine 2007;3(2):201-240. [PubMed: 17557427]

31. McNamara F, Issa FG, Sullivan CE. Arousal pattern following central and obstructive breathing abnormalities in infants and children. J Appl Physiol 1996;81:2651-2657. [PubMed: 9018518]

32. Acebo C, Millman RP, Rosenberg C, Cavallo A, Carskadon MA. Sleep, breathing, and cephalometrics in older children and young adults. Chest 1996;109:664-672. [PubMed: 8617074]

33. Marcus CL, Omlin KJ, Basinki DJ, Bailey SL, Rachal AB, Von Pechmann WS, et al. Normal polysomnographic values for children and adolescents. Am Rev Respir Dis 1992;146(5 Pt 1):12351239. [PubMed: 1443877]

34. Uliel S, Tauman R, Greenfeld M, Sivan Y. Normal polysomnographic respiratory values in children and adolescents. Chest 2004;125(3):872-878. [PubMed: 15006944]

35. Tapia IE, Karamessinis L, Bandla P, Huang J, Kelly A, Pepe M, et al. Polysomnographic values in children undergoing puberty: Pediatric vs. adult respiratory rules in adolescents. Sleep. In press.

36. Rebuffat E, Groswasser J, Kelmanson I, Sottiaux M, Kahn A. Polygraphic evaluation of night-tonight variability in sleep characteristics and apneas in infants. Sleep 1994;17(4):329-332. [PubMed: 7973316]

37. Li AM, Wing YK, Cheung A, Chan D, Ho C, Hui S, et al. Is a 2-night polysomnographic study necessary in childhood sleep-related disordered breathing? Chest 2004;126(5):1467-1472. [PubMed: 15539714]

38. Scholle S, Scholle HC, Kemper A, Glaser S, Rieger B, Kemper G, et al. First night effect in children and adolescents undergoing polysomnography for sleep-disordered breathing. Clin Neurophysiol 2003;114(11):2138-2145. [PubMed: 14580612]

39. Katz ES, Greene MG, Carson KA, Galster P, Loughlin GM, Carroll J, et al. Night-to-night variability of polysomnography in children with suspected obstructive sleep apnea. J Pediatr 2002;140(5):589594. [PubMed: 12032527]

40. Marcus CL, Hamer A, Loughlin GM. Natural history of primary snoring in children. Pediatr Pulmonol 1998;26:6-11. [PubMed: 9710274]

41. Montgomery-Downs HE, O’Brien LM, Gulliver TE, Gozal D. Polysomnographic characteristics in normal preschool and early school-aged children. Pediatrics 2006;117(3):741-753. [PubMed: 16510654]

42. Mason TB, Teoh L, Calabro K, Traylor J, Karamessinis L, Schultz B, et al. Rapid eye movement latency in children and adolescents. Pediatr Neurol 2008;39(3):162-169. [PubMed: 18725060]

43. Witmans MB, Keens TG, Davidson Ward SL, Marcus CL. Obstructive hypopneas in children and adolescents: normal values. Am J Respir Crit Care Med 2003;168(12):1540. [PubMed: 14668259] 


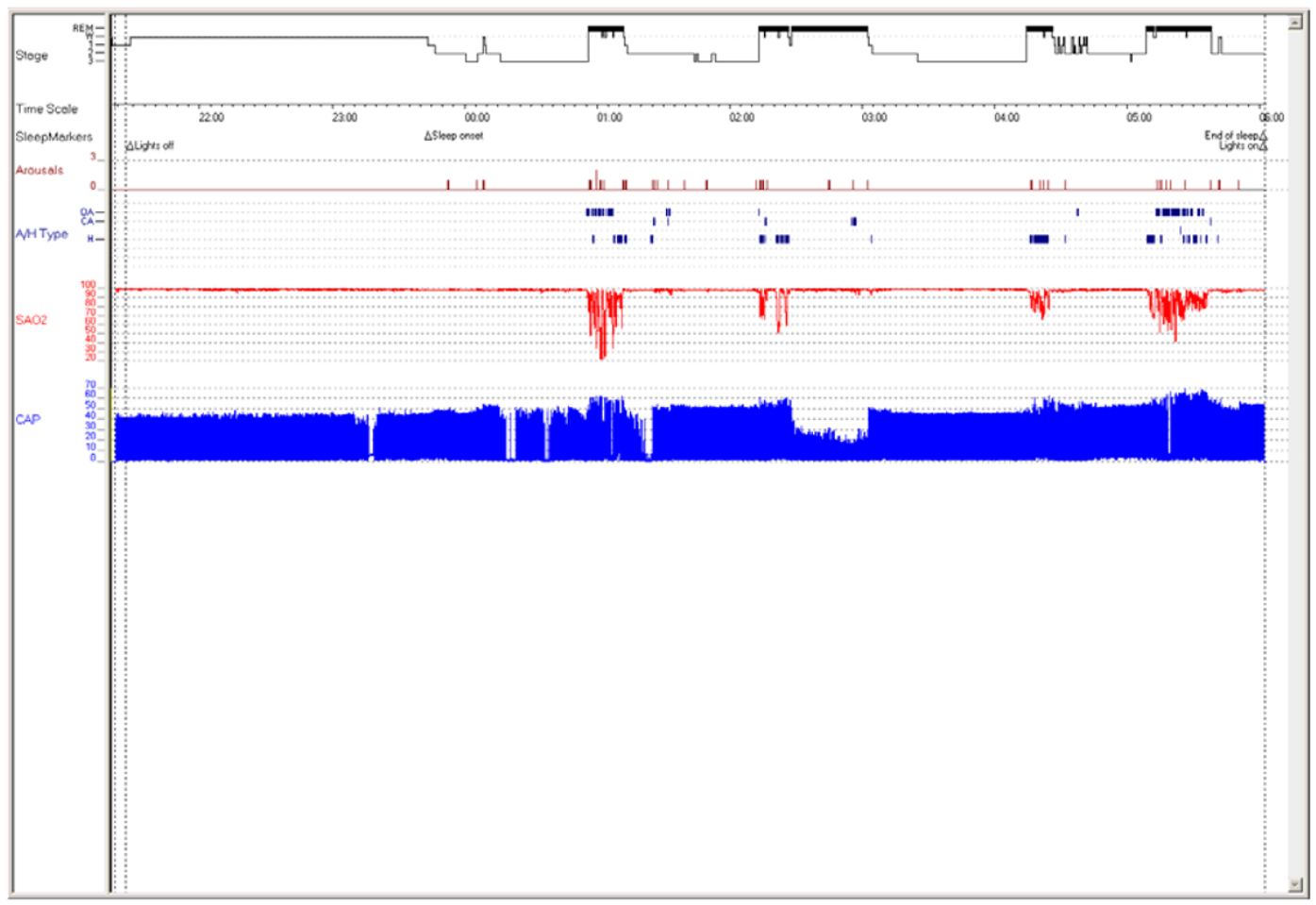

Figure 1.

Hypnogram from a 4 year old girl with obstructive sleep apnea syndrome (OSAS). Note that pediatric OSAS occurs primarily in REM sleep (bold bars), with sleep architecture preserved. Abbreviations: Stage: W: wake, 1: stage N1, 2: stage N2, 3: stage N3; A/H type: Apnea/ hypopnea type: OA: obstructive apnea, CA: central apnea, MA: mixed apnea, H: hypopnea; SAO2: oxygen saturation (\%); CAP: capnography (mm Hg). 


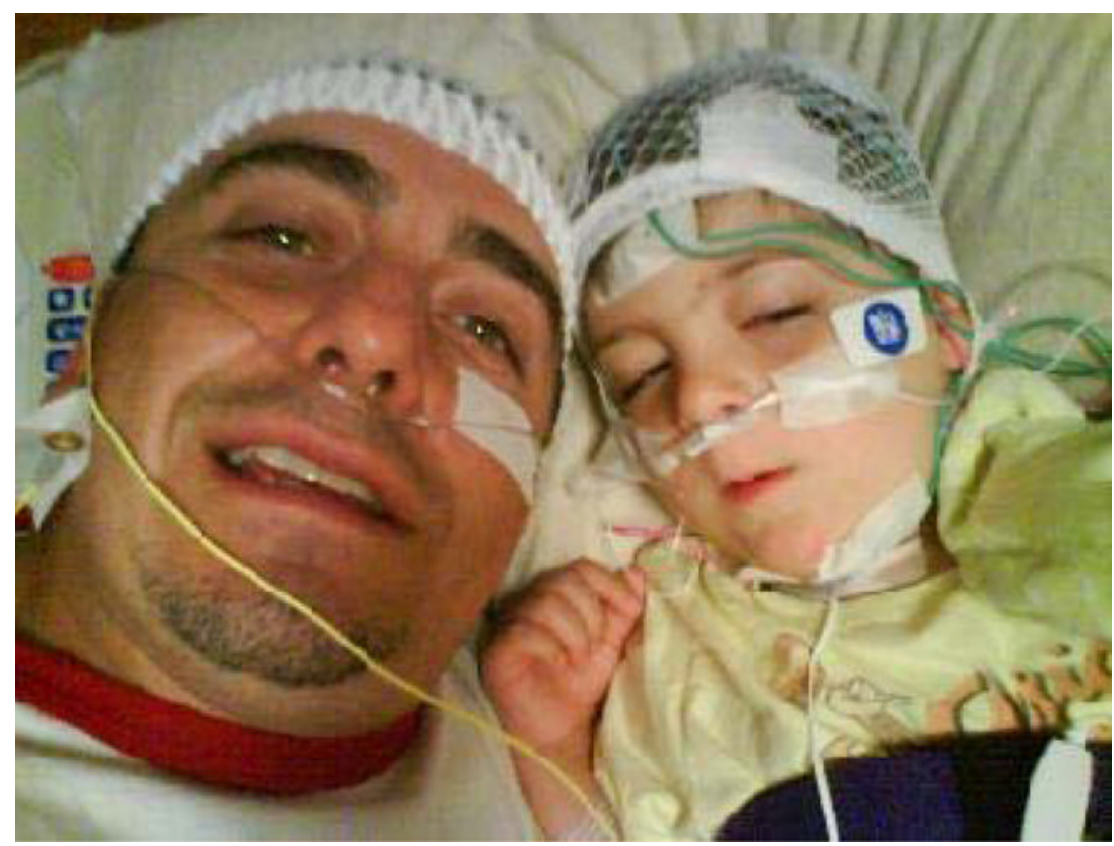

Figure 2.

Photograph of a child and his father just after hook up. Note that the father has engaged in playfully placing a nasal cannula and head wrap on himself as a distraction technique during the hook up. The father took this image with his cell phone at the start of the polysomnogram. 


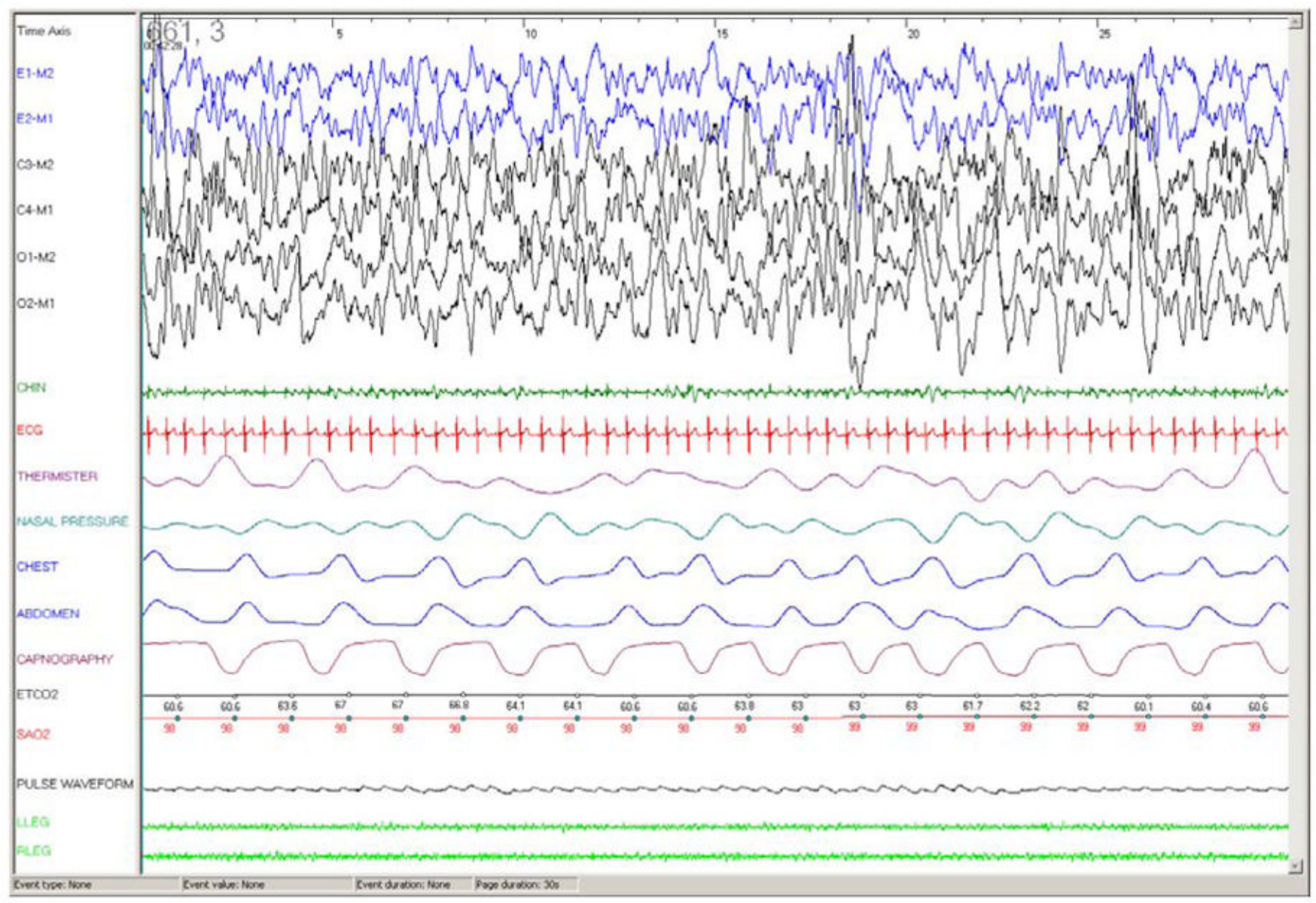

Figure 3.

30 second epoch from a polysomnography recording in a 7 month old girl with meningomyelocele with Arnold Chiari malformation and central hypoventilation. Note excellent $\mathrm{CO} 2$ waveform and good expiratory plateau.

Abbreviations: E1-M2, E2-M1: electrooculogram; C3-M2, C4-M1, O1-M2, O2-M1: EEG;

Chin: chin EMG; ETCO2: end tidal $\mathrm{PCO}_{2}(\mathrm{~mm} \mathrm{Hg}), \mathrm{SAO} 2$ : arterial oxygen saturation (\%). 


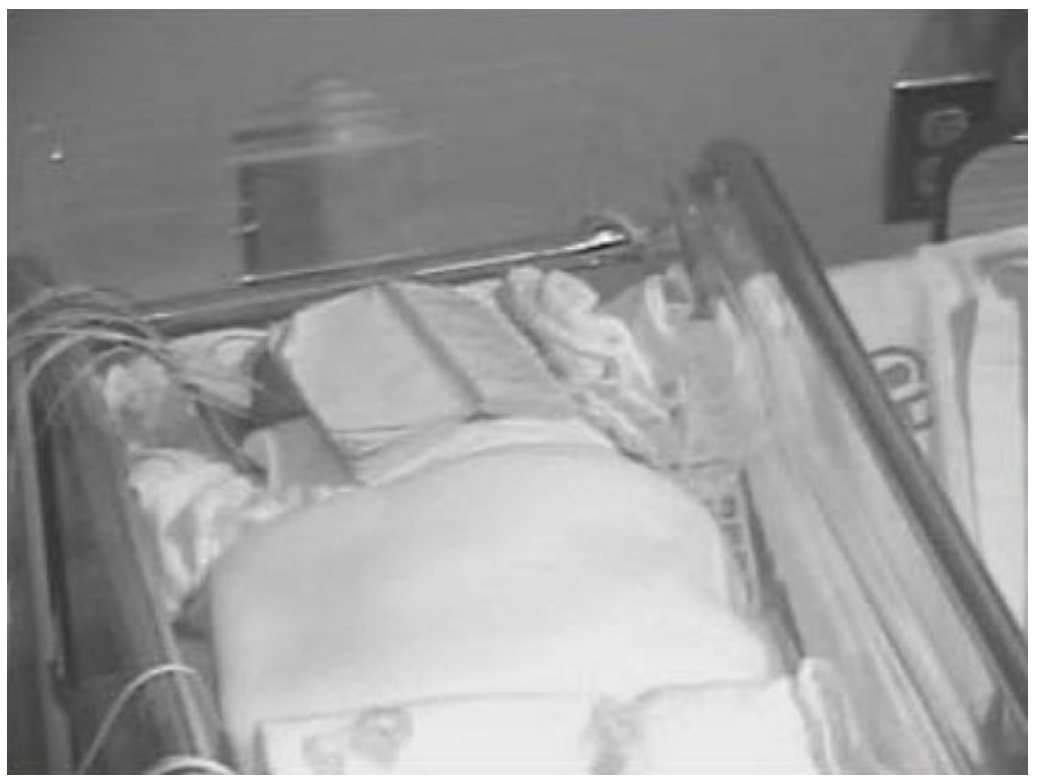

Figure 4.

Still image obtained from an overnight video recording of an 8 week old infant whose parent placed a bible over the child's face in hopes of it benefiting the child, resulting in rebreathing of $\mathrm{CO}_{2}$ without arousal. 


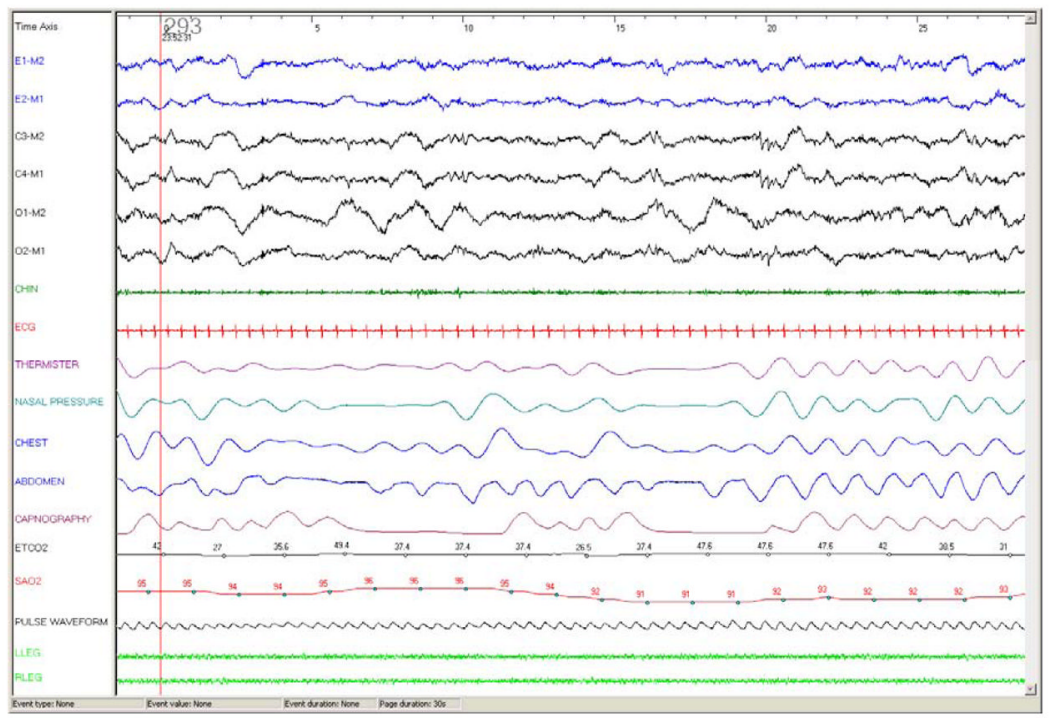

Figure 5.

30 second epoch from a polysomnography recording in a 4 month old infant with OSAS. Note the short duration (4.5-5 seconds) of the obstructive apneas, associated with paradoxical chest and abdominal wall motion and desaturation but no arousal. Ander's sleep staging was used. Abbreviations as per Figure 3. 


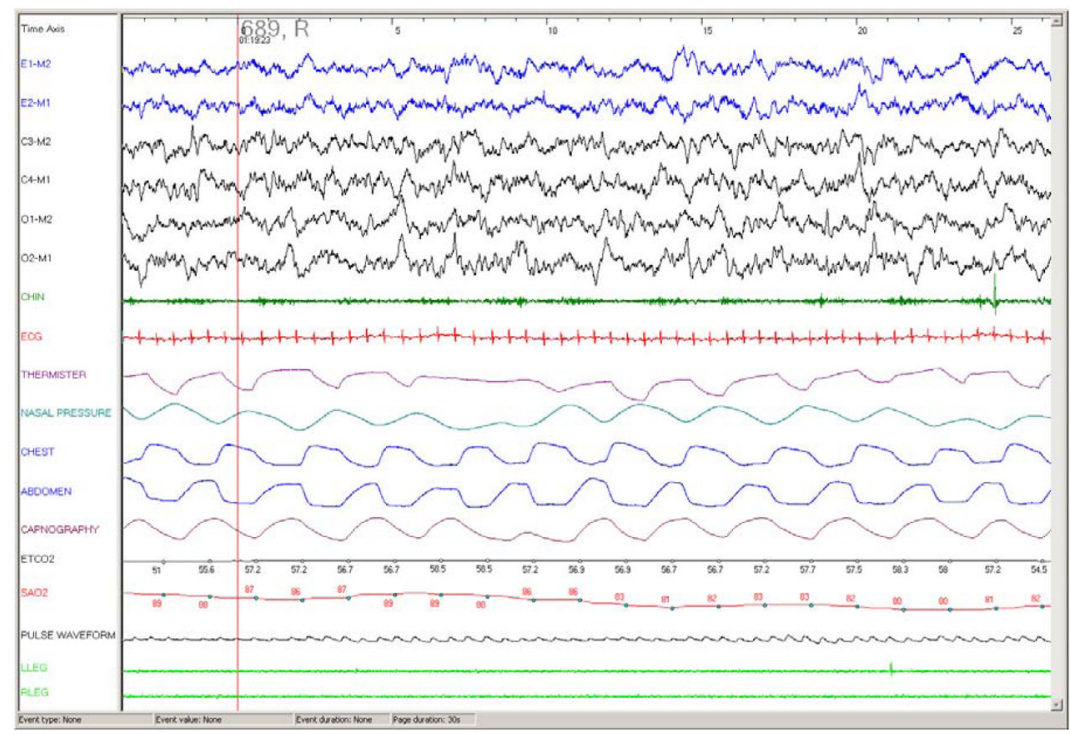

Figure 6.

30 second epoch in a 6 year old otherwise healthy girl with obstructive hypoventilation showing overall preserved nasal airflow with prolonged paradoxical chest and abdominal wall motion, elevated end tidal $\mathrm{CO} 2$ and prolonged desaturation. Abbreviations as per Figure 3. 


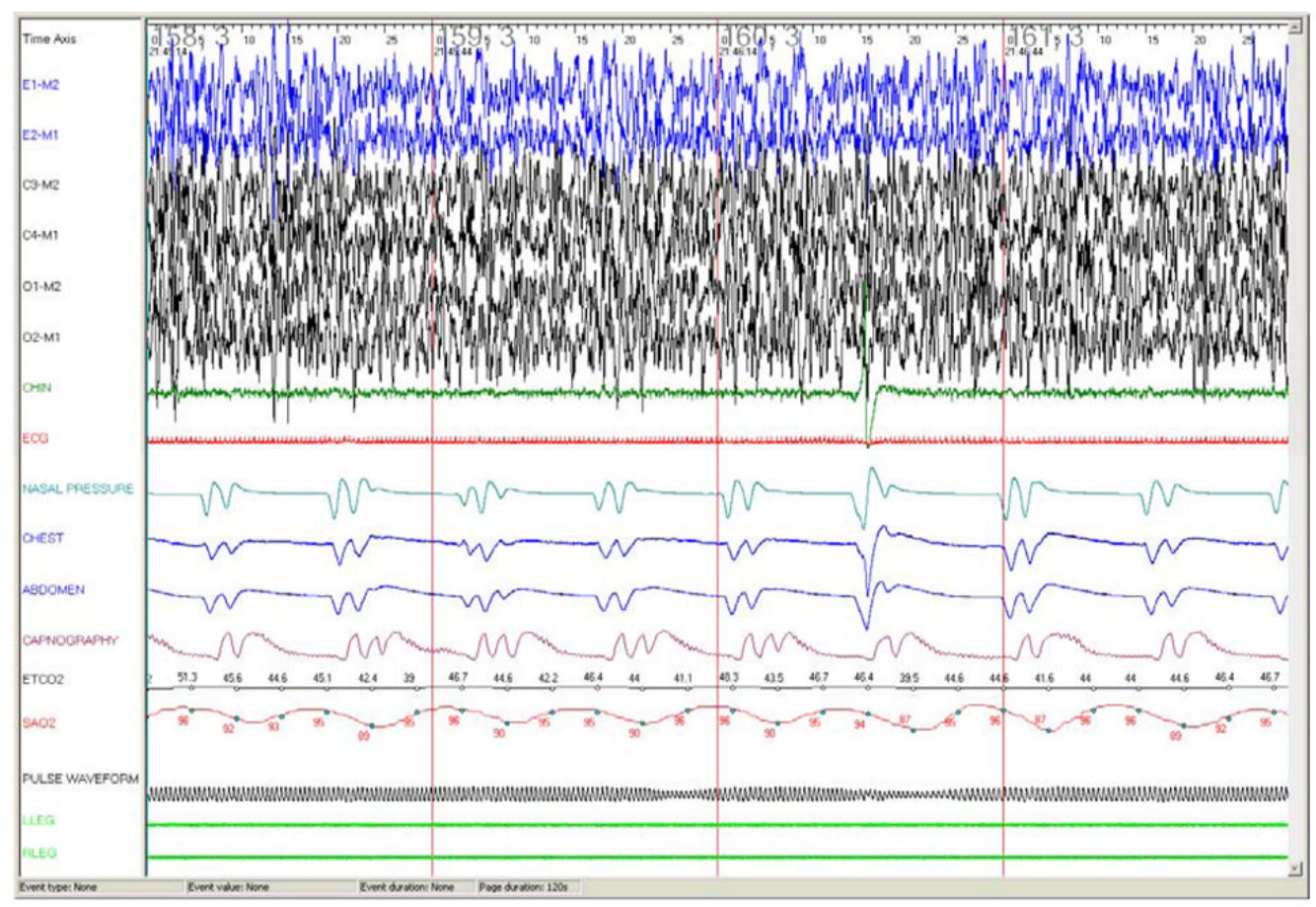

Figure 7.

60 second epoch PSG recording in a 4 month old infant with periodic breathing showing pathological periodic breathing, with characteristic repeated short central apneas and desaturations. Note also high amplitude delta waves, typically seen in infants. Abbreviations as per Figure 3. 
Table 1

Airflow Sensors Used In Pediatric Polysomnography

\begin{tabular}{|l|l|l|l|l|}
\hline Sensor & Methodology & Advantages & Disadvantages & Recommendation \\
\hline Thermistor & $\begin{array}{l}\text { Detects changes } \\
\text { in temperature }\end{array}$ & $\begin{array}{l}\text { Measures oral } \\
\text { as well as nasal } \\
\text { flow }\end{array}$ & $\begin{array}{l}\text { Provides a qualitative } \\
\text { rather than } \\
\text { quantitative } \\
\text { assessment of airflow }\end{array}$ & $\begin{array}{l}\text { AASM recommends } \\
\text { use for detection of } \\
\text { apnea }\end{array}$ \\
\hline Nasal pressure & $\begin{array}{l}\text { Detects changes } \\
\text { in nasal pressure }\end{array}$ & $\begin{array}{l}\text { Provides a } \\
\text { semi- } \\
\text { quantitative } \\
\text { assessment of } \\
\text { airflow }\end{array}$ & $\begin{array}{l}\text { Poor signal in mouth- } \\
\text { breathing patients. } \\
\text { Frequently obstructed } \\
\text { by secretions etc. }\end{array}$ & $\begin{array}{l}\text { AASM recommends } \\
\text { use for detection of } \\
\text { hypopnea }\end{array}$ \\
\hline End-tidal CO2 & Measures PCO 2 & $\begin{array}{l}\text { Provides a } \\
\text { quantitative } \\
\text { assessment of } \\
\text { the PCO }\end{array}$ & $\begin{array}{l}\text { Poor signal in mouth- } \\
\text { breathing patients. } \\
\text { Frequently obstructed } \\
\text { by secretions etc. } \\
\text { May be over-sensitive } \\
\text { in detecting airflow. }\end{array}$ & $\begin{array}{l}\text { Use as a quantitative } \\
\text { measure of PCO } \\
\text { rather than a primary } \\
\text { measure of airflow. }\end{array}$ \\
\hline $\begin{array}{l}\text { Respiratory } \\
\text { inductance } \\
\text { plethysmography } \\
\text { sum signal }\end{array}$ & $\begin{array}{l}\text { Derives tidal } \\
\text { volume from } \\
\text { inanges in } \\
\text { coils }\end{array}$ & $\begin{array}{l}\text { Tolerated well } \\
\text { as no sensors on } \\
\text { face. }\end{array}$ & $\begin{array}{l}\text { Difficult to maintain } \\
\text { calibrated. Cannot } \\
\text { distinguish between } \\
\text { obstructive apnea and } \\
\text { paradoxing from other } \\
\text { causes, e.g., in a young } \\
\text { child or child with } \\
\text { neuromuscular } \\
\text { disease. }\end{array}$ & $\begin{array}{l}\text { Useful for assessing } \\
\text { respiratory effort in } \\
\text { addition to airflow. }\end{array}$ \\
\hline Pneumotachometer & $\begin{array}{l}\text { Measurement of } \\
\text { airflow by } \\
\text { measuring } \\
\text { pressure } \\
\text { differences across } \\
\text { a known } \\
\text { resistance }\end{array}$ & $\begin{array}{l}\text { Quantitative } \\
\text { assessment of } \\
\text { airflow }\end{array}$ & $\begin{array}{l}\text { Requires a snug- } \\
\text { fitting face mask }\end{array}$ & Use in CPAP studies \\
\hline
\end{tabular}


Table 2

Typical Sleep Architecture Values For Normal Children Aged 1-18 Years

\begin{tabular}{|l|l|l|}
\hline Parameter & Usual value & References \\
\hline Sleep efficiency $(\%)$ & $89 \%$, large variability & $(26 ; 41 ; 42)$ \\
\hline Sleep latency (min) & 23, large variability & $(26 ; 41 ; 42)$ \\
\hline REM latency (min) & $\begin{array}{l}87-155(<10 \text { years of age) } \\
136-156(>10 \text { years of age) }\end{array}$ & $(41 ; 42)$ \\
\hline Arousal index (N/hr) & $9-16$ & $(26 ; 41 ; 42)$ \\
\hline Stage N1 (\%TST) & $4-5$ & $(26 ; 34 ; 42)$ \\
\hline Stage N2 (\%TST) & $44-56$ & $(26 ; 34 ; 42)$ \\
\hline Stage N3 (\%TST) & $29-32(<10$ years of age) & $(26 ; 34 ; 42)$ \\
\hline Stage R (\%TST) & $20(>10$ years of age) & $(26 ; 34 ; 42)$ \\
\hline
\end{tabular}

Data are approximated from mean and median values provided in references from large studies of normal children. Sleep stage distributions from reference (41) are not provided as data in that study are quoted as percent of total sleep period and not \% TST. TST, total sleep time. 
Table 3

Recommended Normative Polysomnographic Values For Children Aged 1-18 Years

\begin{tabular}{|l|l|l|}
\hline Parameter & Usual value & Comments and references \\
\hline Obstructive $\mathrm{AHI}(\mathrm{N} / \mathrm{hr})$ & $\leq 1.4$ & $(26 ; 33 ; 41 ; 43)$ \\
\hline Central apnea index $(\mathrm{N} / \mathrm{hr})$ & $\leq 0.4$ & $(26)$ Only study using AASM criteria \\
\hline Time with $\mathrm{SpO}_{2}<90 \%(\% \mathrm{TST})$ & 0 & $(41)$ \\
\hline $\mathrm{SpO}_{2}$ nadir $(\%)$ & $\geq 91$ & $\begin{array}{l}(33 ; 34) \text { (Data from (26) were discrepant, with a value of } \\
86 \%)\end{array}$ \\
\hline $\begin{array}{l}\text { Time with peak } \mathrm{PCO}_{2} \geq 50 \mathrm{~mm} \mathrm{Hg} \\
(\% \mathrm{TST})\end{array}$ & $>25$ & $\begin{array}{l}\text { Data are from (41). Values from (34) were much lower than } \\
\text { references (33;41) and are not consistent with the authors' } \\
\text { personal experience; reference (33) did not use infrared } \\
\text { capnometry and is therefore not included. }\end{array}$ \\
\hline $\begin{array}{l}\text { Periodic limb movement index }(\mathrm{N} / \\
\text { hr) }\end{array}$ & $\leq 4.3$ & \begin{tabular}{l}
$(26 ; 41)$ \\
\hline
\end{tabular}
\end{tabular}

Recommended data derived from the mean \pm 2 standard deviations based upon the highest value from comparable values resulting from large studies. Discordant data are commented upon separately. TST, total sleep time. 